\title{
Introduction from the VA SIG Leadership
}

Denise Adams ${ }^{1}$, Leonardo Brandao ${ }^{2}$, Cameron Trenor $^{3}$, Ionela Iacobas ${ }^{4}$, Adrienne Hammill $^{5}$, and Francine Blei ${ }^{6}$

${ }^{1}$ The Children's Hospital of Philadelphia

${ }^{2}$ Hospital for Sick Children

3Boston Children's

${ }^{4}$ Baylor College of Medicine

${ }^{5}$ Cincinnati Children's Hospital Medical Center

${ }^{6}$ Co-Director, Vascular Anomalies Program of Lenox Hill Hospital

October 28, 2020

\section{Hosted file}

PBC Supplement Introduction 10.27.2020 As Submitted.pdf available at https://authorea.com/ users/370836/articles/489359-introduction-from-the-va-sig-leadership 